\title{
INTERVENÇÃO ERGONOMIZADORA EM BANHEIROS DE USO COLETIVO
}

\section{ERGONOMIZING INTERVENTION IN BATHROOMS FOR COLLECTIVE USE}

\author{
Nora Alejandra Patricia Rebollar ${ }^{1}$, Dr \\ Paola Beatriz May Rebollar ${ }^{2}$, Dr \\ Victor Barbosa do Carmo ${ }^{3}$, M.Sc \\ (1) Faculdade Nova Palhoça - FATENP \\ nora.rebollar@unigranrio.edu.br \\ (2) Faculdade CESUSC \\ paola.rebollar@gmail.com \\ (3) Faculdade Nova Palhoça-FATENP \\ victor.carmo@unigranrio.edu.br
}

Palavras-chave: Ergonomia, Mobiliário, Conforto.

Mobiliário é a expressão que se refere a qualquer elemento funcionalmente independente das paredes, do piso e do teto da edificação. Apesar de existirem diversos estudos acerca do mobiliário, poucas análises fazem referências ao mobiliário dos banheiros de uso coletivo e sua interação com os usuários. O objetivo deste artigo é analisar a interação dos usuários de banheiros masculinos de uso coletivo com os mictórios. O método empregado está dividido em três etapas: Apreciação Ergonômica, Diagnose Ergonômica, Projetação Ergonômica. Foram analisados banheiros masculinos de uso coletivo em interiores de bares, restaurantes, shoppings e instituições de ensino superior. Os resultados mostraram que os mictórios coletivos eram utilizados por no máximo dois usuários em um espaço que poderiam ser instalados três ou mais mictórios individuais. O terceiro usuário sempre se dirigia para os vasos sanitários, onde a utilização de água na descarga é elevada. Portanto, os mictórios coletivos se mostraram ineficientes ao seu propósito porque utilizam mais água para drenagem, ocupam espaço que não é utilizado e não oferecem privacidade aos usuários. Sugere-se barrar o cone visual do usuário completamente como uma decisão de projeto capaz de aumentar a eficiência dos banheiros masculinos de uso coletivo. O uso dos banheiros é inerente a todos os usuários e promover uma sensação positiva é significativo no processo de atração e fidelização dos usuários/clientes.

Realização:

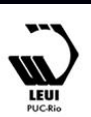


$16^{\circ}$ Ergodesign - Congresso Internacional de Ergonomia e Usabilidade de Interfaces Humano Tecnológica: Produto, Informações Ambientes Construídos e Transporte

$16^{\circ}$ USIHC - Congresso Internacional de Ergonomia e Usabilidade de Interfaces Humano Computador

CINAHPA | 2017 - Congresso Internacional de Ambientes Hipermídia para Aprendizagem.

\section{Key-word: Ergonomics, Furniture, Comfort.}

Furniture is the expression that refers to any element functionally independent of the walls, floor and ceiling of the building. Although there are several studies about the furniture, few analyzes make reference to the furniture of the bathrooms of collective use and their interaction with the users. The purpose of this article is to analyze the interaction of male users of collective bathrooms with urinals. The method employed is divided into three steps: Ergonomic Appreciation, Ergonomic Diagnosis, Ergonomic Projection. Male bathrooms for collective use in bars, restaurants, shopping malls and higher education institutions were analyzed. The results showed that the collective urinals were used by at most two users in a space that could be installed three or more individual urinals. The third user always went to the toilets, where the use of water in the discharge is high. Therefore, the collective urinals were inefficient to their purpose because they use more water for drainage, occupy space that is not used and do not offer users privacy. It is suggested to bar the user's visual cone completely as a design decision capable of increasing the efficiency of male bathrooms for collective use. The use of the bathrooms is inherent to all users and to promote a positive feeling is significant in the process of attraction and loyalty of users / clients.

\section{Introdução}

Mobiliário é a expressão que se refere a qualquer elemento funcionalmente independente das paredes, do piso e do teto que delimitam o espaço em que este se insere (BOOTH \& PLUNKETT, 2015). O mobiliário visa atender aos aspectos funcionais que os ambientes demandam ao mesmo tempo em que atribuem a estes uma qualidade estética e uma identidade.

O mobiliário está intimamente ligado à edificação, mas precisa ser mais sensível que esta. As dimensões e demais características físicas das edificações influenciam a forma como os espaços interiores serão projetados e mobiliados. O mobiliário tem uma importância fundamental no refinamento das instalações e na interação física entre o espaço e os usuários. É através do mobiliário que os usuários interagem com o espaço através do contato físico e visual e da vivência de sua eficiência prática e da sua expressão estética.

A forma do mobiliário tem relação muito próxima com sua função. As formas genéricas evoluem constantemente através do trabalho dos designers visando melhorar e enriquecer a experiência humana nos espaços interiores. Mobiliário e usuários se influenciam mutuamente.

Historicamente, a lógica para elaboração e construção de mobiliário foi predominantemente funcional. Fazia-se uma cadeira para sentar, mesas são horizontais etc. As dimensões destes móveis eram limitadas e determinadas pelo corpo dos usuários. Ao longo do tempo, a tipologia, os métodos construtivos e os materiais empregados no mobiliário foram se complexificando da mesma forma que a sociedade. Nos últimos cinqüenta anos, o desenvolvimento do design de móveis foi exponencial incorporando cada vez mais elementos específicos e linguagens estéticas para além da funcionalidade. Os anos 1970 e 1980 apresentaram um ápice nesta evolução porque nesta época foi possível compreender que a função era apenas um dos componentes que os usuários buscavam em sua interação com os espaços interiores, ou seja, que a praticidade não é o único elemento a ser considerado mas também o valor estético. Este processo levou a radicalismos onde a função se perdeu completamente em oposição a expressão e a
Realização:

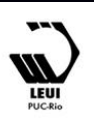




\section{$16^{\circ}$ \\ ERGODESIGN USIHC CINAHPA}

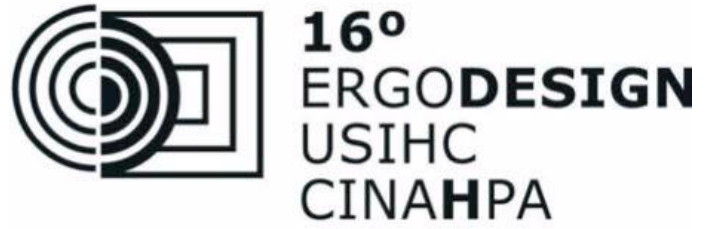

experimentação.

Mais recentemente, a produção de mobiliário evoluiu no sentido de promover uma racionalização do processo de produção com a redução do desperdício de materiais, o reuso, a reciclagem e a utilização de materiais com menor impacto ambiental. Além desta tendência, observa-se atualmente uma ênfase na necessidade de considerar as demandas do desenho universal no desenvolvimento de mobiliário, especialmente aqueles de uso coletivo. Apesar de ainda não existir uma legislação específica neste aspecto, a ética atual demanda esta preocupação por parte do designer.

O planejamento e desenvolvimento de mobiliário envolve um processo colaborativo, pelo menos, três elementos: o designer, o usuário/cliente e o fabricante. Esta colaboração é fundamental para garantir a eficiência do produto final.

Apesar de existirem diversos estudos e recomendações acerca do mobiliário em geral, poucas pesquisas e análises fazem referências ao mobiliário empregado em banheiros de uso coletivo e a forma como os usuários interagem com estes. Qualquer profissional da área consegue citar rapidamente as necessidades deste tipo de espaço, mas poucos param para refletir de que forma ocorre a interação entre os usuários e o mobiliário empregado. Neste espaço interior, os mictórios em especial são mobiliários que demandam um planejamento coerente para que seja possível aproveitar o espaço, reduzir o consumo de água e promover o conforto dos usuários de forma eficiente, mas que são pouco analisados. Diante disso, pretende-se com este artigo analisar a interação dos usuários de banheiros masculinos de uso coletivo com os mictórios.

\section{MÉTODO}

$16^{\circ}$ Ergodesign - Congresso Internacional de Ergonomia e Usabilidade de Interfaces Humano Tecnológica: Produto, Informações Ambientes Construídos e Transporte

$16^{\circ}$ USIHC - Congresso Internacional de Ergonomia e Usabilidade de Interfaces Humano Computador

CINAHPA | 2017 - Congresso Internacional de Ambientes Hipermídia para Aprendizagem.

Este estudo é baseado no método denominado Intervenção Ergonomizadora proposto por Moraes (2009), que agrega técnicas das ciências sociais e de engenharia através da observação e descrição de comportamentos de usuários de banheiros de uso coletivo. A pesquisa se dividiu em três etapas: (1) Apreciação Ergonômica, (2) Diagnose Ergonômica, (3) Projetação Ergonômica.

Foram analisados banheiros masculinos de uso coletivo em interiores de quatro tipos de estabelecimentos que oferecem serviços: bares, restaurantes, shoppings e instituições de ensino superior.

A variável independente adotada neste estudo foi o tipo de mictório instalado (individual ou coletivo). Já as variáveis dependentes selecionadas foram: a) o comportamento dos homens ao utilizar o mictório, especialmente quanto a posição relativa em relação aos demais usuários e b) postura corporal ao utilizar o referido mobiliário.

As observações para a Apreciação Ergonômica foram realizadas durante os meses de julho, agosto, setembro, outubro e novembro de 2016. Foram realizados cinco períodos de observação em cada banheiro dos estabelecimentos, permanecendo em torno de dez minutos sem que os usuários notassem que estavam sendo observados. Durante as observações foram feitas anotações em caderneta de campo, bem como, registros fotográficos quando os banheiros estivessem vazios. No mês de dezembro foi elaborada a Diagnose Ergonômica de cada estabelecimento. Em janeiro e fevereiro de 2017 foi realizada a Projetação Ergonômica para mictórios de banheiros públicos com base nas informações coletadas e na antropometria dos homens dentro do percentil de 95 .

\section{RESULTADO E DISCUSSÃO}

a) Apreciação Ergonômica
Realização:

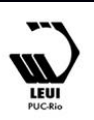




\section{$16^{\circ}$ \\ ERGODESIGN USIHC CINAHPA}

$16^{\circ}$ Ergodesign - Congresso Internacional de Ergonomia e Usabilidade de Interfaces Humano Tecnológica: Produto, Informações Ambientes Construídos e Transporte

$16^{\circ}$ USIHC - Congresso Internacional de Ergonomia e Usabilidade de Interfaces Humano Computador

CINAHPA | 2017 - Congresso Internacional de Ambientes Hipermídia para Aprendizagem.
Com relação aos tipos de mictórios mais utilizados pelos estabelecimentos foi observado que, em geral, nos restaurantes, shoppings e instituições de ensino superior foram instalados mictórios individuais com pequenas divisórias em placas de granito ou painéis de MDF. Na maioria dos bares visitados, os mictórios instalados eram do tipo coletivo, feitos de inox ou de alvenaria revestidos com cerâmica sem nenhum tipo de separação.

Nos mictórios coletivos foi observado que quando este não estava sendo utilizado por ninguém o primeiro usuário do banheiro sempre se direcionava ao mictório, se posicionando em um dos cantos. Durante esta utilização, quando um segundo usuário entrava no banheiro e percebia que o mictório era coletivo e já estava sendo utilizado, parava de caminhar, olhava para os lados procurando a sessão de vasos sanitários e buscava maior privacidade para realizar sua necessidade. No entanto, este perfil, normalmente, não sentia necessidade de fechar a porta, mostrando que somente uma divisão lateral era suficiente. Outra situação observada nestes tipos de mictório coletivo, porém com menos freqüência, apresentava o segundo usuário que, ao perceber que o equipamento já estava sendo utilizado, decidia realizar sua necessidade no mesmo local. Nesta situação os dois usuários se posicionavam nas extremidades do mictório com o corpo virado, o máximo possível, para lados opostos do ambiente.

Nos estabelecimentos que instalaram mictórios individuais foi observado que mesmo quando já havia um usuário na ala de mictório, o segundo usuário não mudava a sua direção de caminhamento e ia diretamente para um dos mictórios vagos. Durante os períodos de observação nenhum usuário ficou constrangido por já haver um primeiro usuário e se direcionou para os vasos sanitários (como foi observado no caso dos mictórios coletivos). Foi observado que neste caso o segundo ou terceiro usuário jamais escolheu um mictório imediatamente ao lado de outro que já estava sendo utilizado. A escolha mais comum era o mictório mais distante possível. No entanto, em ocasiões onde já havia mais de dois usuários, um terceiro usuário ocupava um mictório adjacente. $\mathrm{Na}$ maioria das situações observadas em que mais da metade dos mictórios estavam sendo utilizados, os novos usuários ao ver que teriam ocupar um mictório entre dois já sendo utilizados assumiam a mesma postura observada nos mictórios coletivos. Nestes casos, o novo usuário parava de caminhar, olhava para os lados procurando a sessão de vasos sanitários e buscava maior privacidade para realizar sua necessidade.

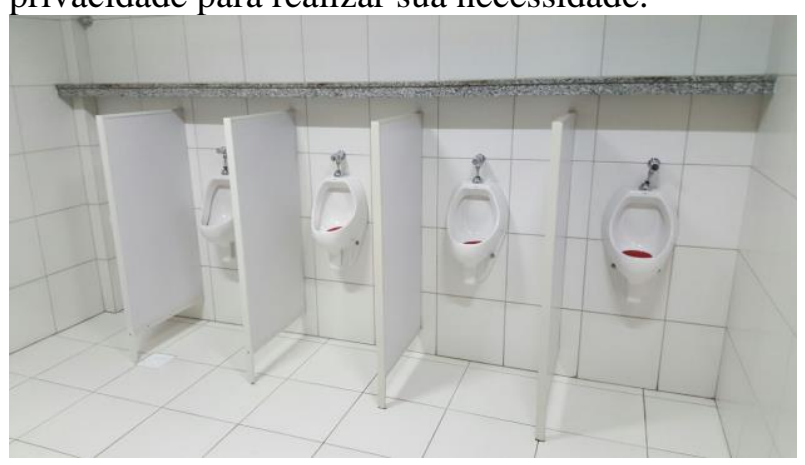

Figura 1: Exemplo de mictório individual com divisória baixa. Fonte: autor.

\section{b) Diagnose Ergonômica}

Os projetistas de banheiros de uso coletivo que escolheram mictórios coletivos como mobiliário alegaram que esta escolha visou atender o maior número de pessoas possível ao mesmo tempo. A partir da observação do comportamento dos usuários dos banheiros onde foram instalados mictórios coletivos, foi possível diagnosticar que o intuito do estabelecimento de atender o maior número de pessoas em um espaço reduzido não foi alcançado. Ao contrário, a economia almejada em espaço, equipamentos hidráulicos e utilização de água tiveram efeito reverso. A Apreciação Ergonômica mostrou que os mictórios coletivos eram utilizados por no máximo dois usuários em um espaço que poderiam ser instalados três ou mais mictórios individuais (figura 2). O terceiro usuário sempre 


\section{$16^{\circ}$ \\ ERGODESIGN USIHC CINAHPA}

se dirigia para os vasos sanitários, onde a utilização de água na descarga é elevada. Portanto, os mictórios coletivos se mostraram ineficientes ao seu propósito porque utilizam mais água para drenagem (por terem maior área) e ocupam espaço que não é utilizado.

Além disso, ficou claro que este tipo de banheiro causa constrangimentos nos usuários. Este tipo de instalação mostrou que não proporciona $o$ mínimo de privacidade aos usuários. A falta de privacidade e o constrangimento reduzem a eficiência do ambiente projetado.

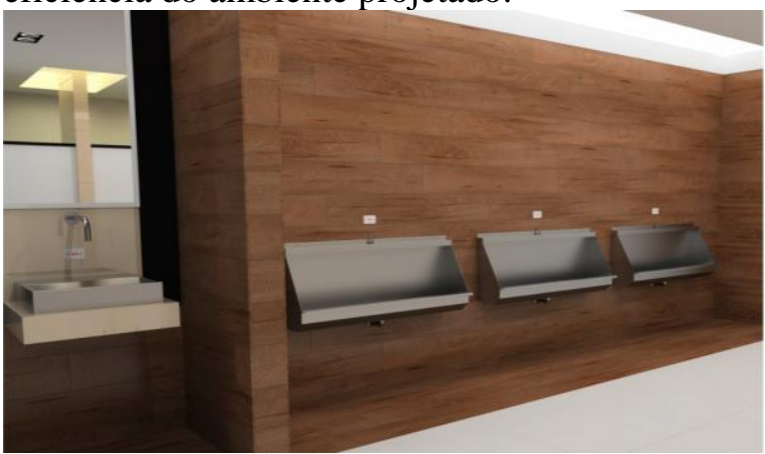

Figura 2: Exemplo de mictório coletivo sem divisória. Fonte: www.palmetal.com.br

Nos estabelecimentos que instalaram mictórios individuais foi observado que os usuários dispõem de um pouco mais de privacidade para realizar sua necessidade do que nos mictórios coletivos. Mas esta sensação de privacidade não era plenamente desfrutada por todos os usuários porque as divisórias instaladas não eram adequadas como ficou demonstrado pela resistência dos usuários na não utilização de mictórios adjacentes. A Apreciação Ergonômica mostrou que as divisórias entre os mictórios foram instaladas até a altura do peito dos usuários, desta forma não barrando o cone visual em nenhum dos casos observados. Os projetos dos mictórios individuais observados foram mais eficientes em atender o maior número de pessoas concomitantemente, mas apenas até o limite de usuários representado pela metade dos mictórios instalados. $16^{\circ}$ Ergodesign - Congresso Internacional de Ergonomia e Usabilidade de Interfaces Humano Tecnológica: Produto, Informações Ambientes Construídos e Transporte

$16^{\circ}$ USIHC - Congresso Internacional de Ergonomia e Usabilidade de Interfaces Humano Computador

CINAHPA | 2017 - Congresso Internacional de Ambientes Hipermídia para Aprendizagem.

\section{c) Projetação Ergonômica}

A Projetação Ergonômica tem o intuito de propor um modelo de projeto que supere as dificuldades encontradas anteriormente. $\mathrm{O}$ novo projeto de mictório precisa barrar o cone visual dos usuários de modo a superar a falta de privacidade observada nas etapas anteriores. De acordo com a tabela antropométrica (PANERO \& ZELNIK, 2012) os homens dentro do percentil 95 apresentam altura dos olhos em pé de $1,74 \mathrm{~m}$, portanto a divisória entre dois mictórios não pode estar abaixo deste valor para garantir privacidade mínima aos usuários. Se o projeto deseja proporcionar privacidade ótima, a altura da divisória deve ter a altura da estatura do usuário, que de acordo com a tabela antropométrica é de $1,84 \mathrm{~m}$ no percentil de 95 . (PANERO \& ZELNIK, 2012).
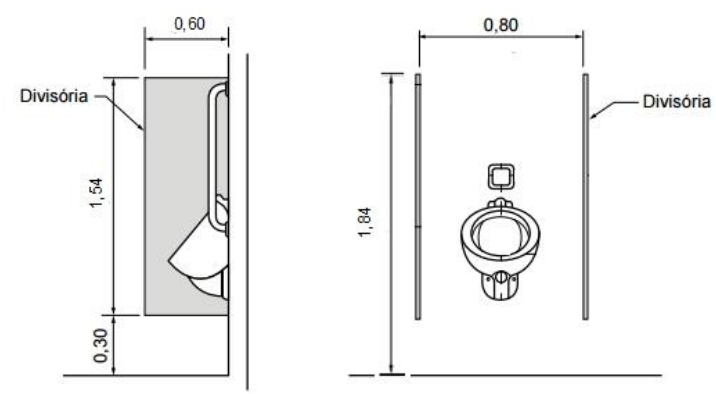

Figura 3: Projeto de mictório proposto.

Fonte: autor.

Sugere-se que barrar completamente o cone visual do usuário através de um nicho individual é uma decisão projetual capaz de aumentar a eficiência dos banheiros masculinos de uso coletivo. Desta maneira, é possível ter melhor aproveitamento do espaço pois todos os mictórios poderão ser utilizados com o mesmo nível de privacidade. Assim como é possível alcançar maior eficiência na utilização da água, pois o usuário não vai se dirigir ao vaso sanitário para urinar apenas por falta de privacidade. E o conforto dos usuários ao utilizar um banheiro coletivo, porém com privacidade, defere a eficiência do projeto. 


\section{$16^{\circ}$ \\ ERGODESIGN USIHC CINAHPA}

$16^{\circ}$ Ergodesign - Congresso Internacional de Ergonomia e Usabilidade de Interfaces Humano Tecnológica: Produto, Informações Ambientes Construídos e Transporte

$16^{\circ}$ USIHC - Congresso Internacional de Ergonomia e Usabilidade de Interfaces Humano Computador

CINAHPA | 2017 - Congresso Internacional de Ambientes Hipermídia para Aprendizagem.
Os banheiros de uso coletivo estão presentes em praticamente todos os ambientes comerciais e institucionais. Apesar desta quase onipresença existem poucas informações, estudos e discussões específicas sobre estes espaços nos livros didáticos e nas publicações científicas. Uma análise de livros de amplo uso nos cursos superiores de arquitetura e design de interiores não possibilitou localizar dados específicos relacionados ao comportamento dos usuários e a eficiência dos banheiros masculinos de uso coletivo (BOOTH \& PLUNKETT, 2015; DUL, 2013; FIALHO et. al., 2005; GOMES FILHO, 2010; GURGEL, 2012; IIDA, 2005; MONT'LVAO, 2012; MORAES, 2009; NEUFERT, 2013; VIEIRA, 2012; PANERO \& ZELNIK, 2015).

O planejamento de espaços interiores é complexo e abrange uma gama de especificidades relacionadas à edificação, ao mobiliário, aos materiais e aos usuários que precisam ser consideradas em profundidade para que seja possível atingir um resultado positivo. Segundo Booth \& Plunkett (2015), um bom planejamento não garante que o ambiente projetado seja eficiente do ponto de vista de sua função: "os usuários devem gostar de permanecer nele e, por isso, dispor-se a aceitar um grau de concessões funcionais" (p.20). Este princípio pode ser aplicado a qualquer tipo de ambiente interior mas normalmente não é considerado no caso dos banheiros de uso coletivo onde o prazer não é visto como relevante. Entretanto, o uso dos banheiros é inerente a todos os usuários e, consequentemente, promover uma sensação positiva é significativo no processo de atração e fidelização dos usuários/cliente.

\section{CONCLUSÃO}

A Diagnose Ergonômica demonstrou que os mictórios observados, coletivos e individuais, não foram eficientes na utilização do espaço disponível e na redução do consumo de água.
Isto ocorreu devido ineficiência dos projetos em proporcionar privacidade aos usuários. Pois estes buscaram a cabine do vaso sanitário ao invés de se dirigir ao mictório onde estavam outros usuários.

A existência de banheiros adequados é fator fundamental para a permanência dos consumidores em estabelecimentos comerciais. O sucesso de um projeto depende de muitos fatores, dentre eles a sensação das pessoas. Outro importante equipamento relacionado aos mictórios é a papeleira higiênica e respectiva lixeira. Dentre os banheiros analisados, somente um em instituição de ensino superior e um em restaurante foram observados tais equipamentos. Neste restaurante foi observado um fato inédito, havia apenas uma papeleira instalada acima da divisória entre os mictórios que deveria ser compartilhada entre os usuários e também não havia uma lixeira logo em baixo.

Portanto, projetos de banheiros confortáveis e eficientes em atender as necessidades individuais dos seus clientes são fundamentais para o sucesso de qualquer empreendimento comercial. Muitos estabelecimento investem em fraldários unisex, revestimentos de granitos e iluminação indireta, mas não se preocupam com a privacidade masculina considerando que este elemento não é importante para os usuários. No entanto, a observação realizada nesta pesquisa permite afirmar que esta acepção não reflete a realidade e os usuário sempre buscam privacidade.

\section{Referências Bibliográficas}

BOOTH, Sam; PLUNKETT, Drew. Mobiliário para o design de interiores. São Paulo: Gustavo Gili, 2015.

DUL, Jan.; WEERDMEESTER, B. Ergonomia

Prática. 3.ed. Sao Paulo, Edgard Blucher, 2013.

FIALHO, Francisco A. P.; BRAVIANO, Gilson;
Realização:

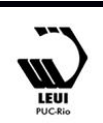




\section{$16^{\circ}$ \\ ERGODESIGN USIHC CINAHPA}

$16^{\circ}$ Ergodesign - Congresso Internacional de Ergonomia e Usabilidade de Interfaces Humano Tecnológica: Produto, Informações Ambientes Construídos e Transporte

$16^{\circ}$ USIHC - Congresso Internacional de Ergonomia e Usabilidade de Interfaces Humano Computador

CINAHPA | 2017 - Congresso Internacional de Ambientes Hipermídia para Aprendizagem.

SANTOS, Neri dos. Métodos e técnicas em ergonomia. Florianópolis: Edição do Autor, 2005.

GOMES FILHO, Joao. Ergonomia do objeto. São Paulo: Escrituras, 2010.

GURGEL, Miriam. Projetando espaços comerciais. São Paulo: Editora Senac, 2007.

IIDA, Itiro. Ergonomia: projeto e produção. São Paulo, Edgard Blucher, 2012.

MONT'LVAO, Claudia. Design, ergonomia, emoção. Rio de Janeiro: Mauad, 2012..

MORAES, Anamaria de. Ergonomia: conceitos e aplicações. Rio de Janeiro: 2AB, 2009.

NEUFERT, Ernst. Arte de projetar em arquitetura. São Paulo: Gustavo Gilli- Brasil, 2013.

PANERO, Julius; ZELNIK, Martin. Dimensionamento humano para espaços interiores. São Paulo: Gustavo Gilli, 2012.

VIEIRA, Jair lot. Manual de ergonomia. São Paulo: Edipro, 2012. 